\title{
O DESENVOLVIMENTO NACIONAL SUSTENTÁVEL COMO DIREITO FUNDAMENTAL À LUZ DA ConstituiçÃo DE 1988

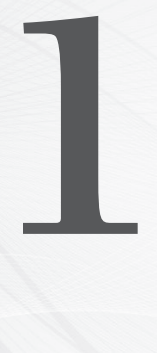

\section{Flávio Augusto de Oliveira Santos}

Advogado.

Recebido em: 02.08.2011

Aprovado em: 17.08.2011

ÁreA do Direito: Constitucional

Resumo: 0 desenvolvimento nacional sustentável é objetivo da República Federativa do Brasil e hoje, um dos temas mais debatidos em um cenário de crescente preocupação ambiental e social. Explora-se o conceito deste e as inter-relações com a dignidade da pessoa humana para levantar o debate sobre a possibilidade de um direito fundamental ser reconhecido por meio das possibilidades oferecidas com a abertura do rol constitucional promovida pelo art. $5 .{ }^{\circ}, \S 2 .{ }^{\circ}$, da CF/1988. Não obstante, divide-se o conceito em um tripé, formado por aspectos econômicos, sociais e ambientais, avaliando o reconhecimento já existente dentro do corpo constitucional, bem como a questão dos tratados internacionais que já cuidam do tema. Finalmente, são postas questões sobre a efetivação deste desenvolvimento, levando em conta as perspectivas objetiva e subjetiva dos direitos fundamentais, e o papel do Judiciário na questão.
ABSTRACT: The national sustainable development is an objective of the Federal Republic of Brazil and, today, one of the most debated themes in a scenario of growing social and environmental concerns. The concept of this development is explored here, together with its relation with the human dignity principle to raise the issue of the possibility of a new fundamental right to be recognized through the possibilities offered with the opening of the constitutional roll, promoted by the fifth article, second paragraph of the Brazilian Federal Constitution. Also, the concept is divided in a tripod formed by economical, social and environmental aspects evaluating the already existing recognition of those aspects inside the constitutional text as well as the matter of the international treaties that verse about the theme. Lastly, questions about the effectiveness of this development are raised, taking in consideration the subjective and objective aspects of the fundamental rights and the function of the judiciary in the matter. 
PaLAVRAS-ChaVE: Desenvolvimento nacional sustentável - Direitos fundamentais - Direito ao desenvolvimento - Constituição.
KeYwords: National susteinable development - Fundamental rights - Right to development Constitution.

SumÁrio: 1. Considerações iniciais - 2. Conceito de desenvolvimento sustentável e a dignidade da pessoa humana - 3. Considerações sobre direitos fundamentais - 4. Desenvolvimento nacional sustentável e dignidade da pessoa humana sob a ótica dos parâmetros do conceito adotado de direitos fundamentais - 5. Conclusões - 6. Referências bibliográficas.

\section{CONSIDERAÇõES INICIAIS}

A Constituição Republicana de 1988 traz em seu art. 3. ${ }^{\circ}$, II, que é objetivo fundamental da República Federativa do Brasil "garantir o desenvolvimento nacional", sem, contudo, definir de forma explícita o que seria este "desenvolvimento", não esclarecendo, assim, o que deveria ser garantido ou mesmo de que forma.

Estudos contemporâneos sobre o tema abordam aspectos econômicos, sociais e ambientais, buscando uma harmonização e tendo como fim a dignidade da pessoa humana. ${ }^{1}$ Dada sua importância, referida dignidade é erigida à condição de princípio, embora "de conceito de contornos vagos e imprecisos" e de parecer "pertencer àquele lote de realidades particularmente avessas à claridade, chegando a dar a impressão de se obscurecer na razão direta do esforço despendido para o clarificar", ${ }^{3}$ e pode ser mais bem delimitada se utilizando o escólio de Ingo Wolfgang Sarlet: ${ }^{4}$

"O conceito que se propõe, vale repisar, representa uma proposta em processo de construção, visto que já sofreu dois ajustes desde a primeira edição,

1. Neste sentido, destaque-se que a dignidade da pessoa humana é princípio fundamental da República Federativa do Brasil, previsto como tal no art. 1. ${ }^{\circ}$, III, da CF/1988.

2. Maunz, Theodor; Zippelius, Reinhold. Deutsches Staatsrecht. 29. ed. Munchen: C.H. Beck, 1994. p. 179.

3. Alexandrino, Jose de Melo. Perfil constitucional da dignidade da pessoa humana: um esboço traçado a partir da variedade de concepções. Estudos em honra ao Professor Jose Ascensão. Coimbra: Almeida, 2008. vol. I, p. 481.

4. SARlet, Ingo Wolfgang. Dignidade da pessoa humana e direitos fundamentais na Constituição Federal de 1988. 9. ed. Porto Alegre: Livraria do Advogado, 2011. p. 73. 
com o intuito da máxima afinidade possível com uma concepção multidimensional, aberta e inclusiva de dignidade da pessoa humana. Assim sendo, temos por dignidade da pessoa humana a qualidade intrínseca e distintiva reconhecida em cada ser humano que o faz merecedor do mesmo respeito e consideração por parte do Estado e da comunidade, implicando, neste sentido, um complexo de direitos e deveres fundamentais que assegurem a pessoa tanto contra todo e qualquer ato de cunho degradante e desumano, como venham a lhe garantir as condições existenciais mínimas para uma vida saudável, além de propiciar e promover sua participação ativa e corresponsável nos destinos da própria existência e da vida em comunhão com os demais seres humanos, mediante o devido respeito ao demais seres que integram a rede da vida".

Assim sendo, resta patente a possibilidade de uma correlação entre o desenvolvimento nacional e o princípio da dignidade da pessoa humana, o que faz exsurgir a seguinte questão: estar-se-á tratando aqui de um direito fundamental, haja vista os aspectos que aborda e o fim a que se presta?

Com esta indagação em mente, neste ensaio se investigam os conceitos construídos pela doutrina acerca do desenvolvimento, sempre verificando sua ligação com a dignidade da pessoa humana e sua contextualização frente às definições contemporâneas de direitos fundamentais, mormente para fins de análise no contexto da Constituição Federal de 1988. Destarte, assume relevo o art. $5 .^{\circ}$, § 2. ${ }^{\circ}$, da CF, para fins de cogitação das eventuais consequências do reconhecimento do desenvolvimento nacional como direito fundamental, especialmente tendo em vista o $\& 1 .^{\circ}$ do mesmo dispositivo constitucional.

\section{Conceito de desenvolvimento sustentável e A Dignidade da PeSSOA HUMANA}

A preocupação com uma ideia de desenvolvimento que reconhecesse a máxima econômica da escassez dos recursos remonta à década de 1950, um período ainda fortemente influenciado pela Segunda Guerra Mundial que causou grande impacto no crescimento econômico global, bem como na utilização dos recursos naturais.

No entanto, os primeiros estudos relevantes começaram a aparecer no final da década de 1960, início de 1970. Dentre eles, destaca-se o relatório de Donella Meadows intitulado originalmente de Limits to Growth, ${ }^{5}$ que trabalhava

5. Meadows, Donella H.; Meadows, Dennis L.; Randers, Jorgen; Behrens, William W. Limites do crescimento: um relatório para o projeto do clube de Roma sobre o dilema da humanidade. 2. ed. São Paulo: Perspectiva, 1978. p. 58. 
com a ideia de que uma manutenção do crescimento populacional, industrial e da poluição, conjuntamente com o crescente déficit de produção alimentar e o esgotamento dos recursos naturais, faria com que o limite de crescimento do planeta fosse atingido em no máximo cem anos. ${ }^{6}$

Uma das mais interessantes qualidades do ensaio é a divisão dos estudos de impacto do crescimento (não sustentável) em três áreas, quais sejam "Sociedade", "Economia" e "Meio Ambiente", ${ }^{7}$ o que reflete amplamente na criação dos conceitos contemporâneos de desenvolvimento sustentável, dentre os quais o estabelecido pela Comissão Mundial sobre o Meio Ambiente e Desenvolvimento (WCED): "Desenvolvimento sustentável é o desenvolvimento que satisfaz as necessidades do presente sem comprometer a capacidade de as futuras gerações satisfazerem suas próprias necessidades". ${ }^{8}$ Em verdade, dito conceito foi uma releitura do "Princípio l" estabelecido na Convenção das Nações Unidas sobre Meio Ambiente e Desenvolvimento Humano, realizada em Estocolmo (1972) que assim determinava: "O homem tem o direito fundamental à liberdade, à igualdade e ao desfrute de condições de vida adequadas, em um meio ambiente de qualidade tal que lhe permita levar uma vida digna, gozar de bem-estar e é portador solene de obrigação de proteger e melhorar o meio ambiente, para as gerações presentes e futuras". ${ }^{9}$

Evidente, pois, que houve significativa evolução do conceito de desenvolvimento sustentável, visto que Estocolmo (1972) e a WCED (1983) ainda trabalhavam com ideias brutas sobre tema, enfrentando grupos radicais; de um lado os defensores de um crescimento a qualquer custo e, de outro, os adeptos do chamado "zegismo", ${ }^{10-11}$ duramente criticado na atualidade. Ignacy Sachs, por exemplo, afirma que "deixar de crescer visando unicamente se livrar dos impactos negativos do crescimento sobre o meio ambiente é uma proposição intelectualmente ingênua e politicamente suicida". ${ }^{12}$

6. Idem, ibidem.

7. Idem, ibidem.

8. WCED. Our common future. Oxford: Oxford University Press, 1987. p. 43.

9. Silva, Geraldo Eulálio do Nascimento. Direito ambiental internacional. 2. ed. Rio de Janeiro: Thex, 2002. p. 322.

10. Termo que se refere a filosofia Zero Economic Growth (crescimento econômico zero).

11. SACHS, Ignacy. A terceira margem: em busca do ecodesenvolvimento. São Paulo: Cia. das Letras, 2009. p. 232.

12. SACHS, Ignacy. Rumo à ecossocioeconomia: teoria e prática do desenvolvimento. São Paulo: Cortez, 2007. p. 96. 
Todavia, já em 1986 a ONU, por meio de sua Res. 41/128, reconhecia desenvolvimento como "processo econômico, social, cultural e político abrangente, que visa ao constante incremento do bem-estar de toda a população e de todos os indivíduos com base em sua participação ativa, livre e significativa no desenvolvimento e na distribuição justa dos benefícios daí resultantes". ${ }^{13}$

Os conceitos mais contemporâneos incorporam melhor a ideia de harmonia entre os três principais estratos de desenvolvimento, como o de Sachs: ${ }^{14}$

“(...) desenvolvimento pode ser compreendido como um processo intencional e autodirigido de transformação e gestão de estruturas socioeconômicas, direcionado no sentido de assegurar a todas as pessoas uma oportunidade de levarem uma vida plena e gratificante, provendo-as de meios de subsistência decentes e aprimorando continuamente seu bem-estar, seja qual for o conteúdo concreto atribuído a essas metas por diferentes sociedades em diferentes momentos históricos."

Assim concebido, o desenvolvimento demonstra abranger aspectos sociais, econômicos e ambientais ao utilizar expressões como "estruturas socioeconômicas", "vida plena e gratificante" e "bem-estar". A importância do meio ambiente, por sua vez, fica mais clara quando se afirma que: "O problema que se coloca, portanto, não consiste na escolha entre crescimento e qualidade do ambiente, mas sim em se tentar harmonizar objetivos socioeconômicos e ambientais mediante a redefinição das modalidades de crescimento e da utilização dos recursos". 15

Mas o pensamento contemporâneo de desenvolvimento que guia este ensaio é o seguinte, de Amartya Sen:

"Os fins e os meios do desenvolvimento requerem análise e exame minuciosos para uma compreensão mais plena do processo de desenvolvimento; é sem dúvida inadequado adotar como nosso objetivo básico apenas a maximização de renda ou de riqueza, que é, como observou Aristóteles - meramente útil e em proveito de alguma outra coisa. Pela mesma razão, o crescimento econômico não pode sensatamente ser considerado um fim em si mesmo. O desenvolvimento tem de estar relacionado sobretudo com a melhora da vida que levamos e das liberdades que desfrutamos. Expandir as liberdades que temos também permite que sejamos seres sociais mais completos, pondo em prática

13. Res. 41/128 da Assembleia Geral das Nações Unidas, de 04.12.1986.

14. SAchs, Ignacy. Rumo à ecossocioeconomia... cit., p. 293.

15. Idem, p. 97. 
nossas volições, interagindo com o mundo em que vivemos e influenciando esse mundo." 16

Isto posto, resta evidente que, para além de um conceito, o mais importante para a análise de um possível direito fundamental é a correlação potencialmente existente entre desenvolvimento nacional sustentável e dignidade da pessoa humana. Sobre a gênese de tal categoria de direitos e o princípio em voga como portador de carga normogenética, confira-se o escólio de Ingo Wolfgang Sarlet: ${ }^{17}$

"(...) já que cada direito fundamental pressupõe - na esteira do que leciona Alexy - necessariamente uma norma jusfundamental que o reconheça, (...) verifica-se que o dispositivo constitucional (texto) no qual se encontra enunciada a dignidade da pessoa humana (no caso, o art. $1 .^{\circ}$, III, da CF/1988), contém não apenas mais de uma norma, mas que esta(s), para além de seu enquadramento na condição de princípio e regra (valor) fundamental, é (são) também fundamento de posições jurídico-subjetivas, isto é, norma(s) definidora(s) de direitos e garantias, mas também de deveres fundamentais".

Desta forma, já é possível começar a compreender a relação entre dignidade da pessoa humana e desenvolvimento nacional sustentável. O primeiro é o fim do segundo, que é origem do primeiro como direito. Não obstante, garantir os vários aspectos do primeiro conceito é fundamental para que haja desenvolvimento, o qual é essencial para a manutenção das condições existenciais para uma vida saudável.

É por esta via que se manifesta Amartya Sen, ${ }^{18}$ ao afirmar que "as liberdades não são apenas os fins primordiais do desenvolvimento, mas também os meios principais", ou seja, como "meio" para o desenvolvimento, é preciso, mais uma vez nas palavras do autor: "(...) que se removam as principais fontes de privação de liberdade: pobreza e tirania, carência de oportunidades econômicas e destituição social sistemática, negligência dos serviços públicos e intolerância ou interferência excessiva de Estados repressivos". ${ }^{19}$

Ainda sobre esta interligação, mais uma vez se pode utilizar os ensinamentos de Amartya $\operatorname{Sen}^{20}$ quando o autor coloca o seguinte:

16. SEn, Amartya Kumar. Desenvolvimento como liberdade. São Paulo: Cia. das Letras, 2000. p. 29.

17. SARlet, Ingo Wolfgang. Op. cit., p. 83.

18. SEN, Amartya Kumar. Op. cit., p. 25.

19. Idem, p. 18.

20. Idem, p. 19. 
"A ligação entre liberdade individual e realização de desenvolvimento social vai muito além da relação constitutiva - por mais importante que ela seja. $\mathrm{O}$ que as pessoas conseguem positivamente realizar é influenciado por oportunidades econômicas, liberdades políticas, poderes sociais e por condições habilitadoras como boa saúde, educação básica e incentivo e aperfeiçoamento de iniciativas."

A esta altura, é importante destacar rapidamente o conteúdo destas liberdades referidas por Amartya Sen, com o intento de demonstrar substantiva ligação com o conceito de dignidade da pessoa humana previamente adotado aqui. $\mathrm{O}$ autor investiga em sua obra cinco tipos de liberdade, as quais enumera da seguinte forma: (a) liberdades políticas, (b) facilidades econômicas, (c) oportunidades sociais, (d) garantias de transparência e (e) segurança protetora, ${ }^{21}$ afirmando que "cada um desses tipos distintos de direitos e oportunidades ajuda a promover a capacidade geral de uma pessoa". ${ }^{22}$

A primeira liberdade se apresenta na forma de liberdade de expressão e eleições livres, o que é necessário para a promoção da segurança econômica. ${ }^{23}$ Ressalte-se aqui que o autor inclui nesta primeira liberdade "o que se denominam direitos civis", ${ }^{24}$ mas o destaque principal é para "às oportunidades que as pessoas têm para determinar quem deve governar e com base em que princípios, além de incluírem a possibilidade de fiscalizar e criticar as autoridades (...)".25

Esta claro aqui que o autor faz referência aos fundamentos do Estado Democrático de Direito. O princípio da dignidade da pessoa humana não faz sentido em um Estado diverso deste. Ainda dentro do conceito de Ingo Sarlet, destaque-se "(...) propiciar e promover sua participação ativa e corresponsavel nos destinos da própria existência e da vida em comunhão". ${ }^{26}$

A segunda liberdade se apresenta na forma de "oportunidade de participação no comércio e na produção, contribuindo para gerar abundância individual bem além de recursos públicos para os serviços sociais", ${ }^{27}$ o autor prossegue

\footnotetext{
21. Idem, p. 25.

22. Idem, p. 26.

23. Idem, p. 25.

24. SEN, Amartya Kumar. Op. cit., p. 55.

25. Idem, ibidem.

26. SARlet, Ingo Wolfgang. Op. cit., p. 73.

27. Sen, Amartya Kumar. Op. cit., p. 26.
} 
afirmando que "à medida que o processo de desenvolvimento econômico aumenta a renda e a riqueza de um país, estas se refletem no correspondente aumento de intitulamentos econômicos da população". ${ }^{28}$

A terceira liberdade apresenta-se na forma de serviços como educação e saúde, o que facilita a participação econômica, ${ }^{29}$ sendo de fundamental importância, visto que "(...) há uma perda social quando se nega às pessoas o direito de interagir economicamente umas com as outras". Ainda segundo o autor, estes serviços "(...) influenciam a liberdade substantiva de o indivíduo viver melhor" ${ }^{30}$

Na segunda, bem como na terceira liberdade, aparecem as características de instrumentalidade (meio) das liberdades para atingir o fim "(...) as condições existenciais mínimas para uma vida saudável (...)". ${ }^{31}$

A quarta liberdade não se relaciona imediatamente com o princípio da dignidade da pessoa humana, mas trabalha com a segurança do Estado Democrático de Direito, cujos fundamentos foram trabalhados pela primeira liberdade, tratam-se de "(...) necessidades de sinceridade que as pessoas podem esperar: a liberdade de lidar uns com os outros sob garantias de dessegredo e clareza (...) essas garantias tem um claro papel instrumental como inibidores da corrupção, da irresponsabilidade financeira e de transações ilícitas". ${ }^{32}$ Cabe enfatizar que esta liberdade encontra par em vários outros princípios do ordenamento pátrio, destacando a moralidade, a publicidade e a probidade administrativa.

Por último, a quinta liberdade trata de vários temas já abarcados pela Constituição Federal de 1988, direitos sociais amplamente reconhecidos no Brasil, uma vez que o autor se refere à segurança protetora como:

"(...) necessária para propiciar uma rede de segurança social, impedindo que a população afetada seja reduzida à miséria abjeta e, em alguns casos, até mesmo à fome e à morte. A esfera da segurança protetora inclui disposições institucionais fixas, como benefícios aos desempregados e suplementos de renda regulamentares para os indigentes, bem como medidas ad hoc, como distribuição de alimentos em crises de fome coletiva ou empregos públicos de emergências para gerar renda para os necessitados." ${ }^{33}$

\footnotetext{
28. Idem, p. 55.

29. Idem, p. 25.

30. Idem, p. 56.

31. Sarlet, Ingo Wolfgang. Op. cit., p. 73.

32. Sen, Amartya Kumar. Op. cit., p. 56.

33. Idem, ibidem.
} 
Aqui, é importante destacar que, para além dos direitos sociais, tratam-se de direitos fundamentais das minorias, mantendo uma conexão mediata com o princípio da dignidade da pessoa humana, visto que visa protegê-la. Ingo Sarlet ${ }^{34}$ refere-se a isso como uma definição negativa do princípio, ensinando da seguinte forma:

"O que se percebe, em última análise, é que onde não houver respeito pela vida e pela integridade física e moral do ser humano, onde as condições mínimas para uma existência digna não forem asseguradas, onde não houver limitação do poder, enfim, onde a liberdade, a autonomia, a igualdade (em direitos e dignidade) e os direitos fundamentais não forem reconhecidos e minimamente assegurados, não haverá espaço para a dignidade da pessoa humana e esta (a pessoa), por sua vez, poderá não passar de mero objeto de arbítrio e injustiças.”

Em última análise, as semelhanças ou correlações entre o princípio da dignidade da pessoa humana e o conceito de desenvolvimento sustentável têm uma explicação lógica. O objetivo de ambos é o ser humano ou a pessoa natural e a garantia de condições de vida sustentada com um mínimo existencial, sendo que, deste ponto em diante, deve haver um progresso cada vez maior (Estado Social).

Isto é o que Amartya Sen resume como finalidade do desenvolvimento, qual seja “ (...) desenvolvimento visto como um processo de expansão das liberdades substantivas das pessoas", 35 sendo muito semelhante às colocações de Ingo Sarlet quando define a antítese da dignidade da pessoa: "Tudo, portanto, converge no sentido de que também para a ordem jurídico-constitucional a concepção de homem-objeto $^{36}$ (ou homem-instrumento), com todas as consequências que daí podem e devem ser extraídas, constitui justamente a antítese da noção de dignidade da pessoa (...)". ${ }^{37}$

Feita até aqui a análise de alguns conceitos de desenvolvimento, bem como da correlação com o princípio da dignidade da pessoa humana, resta agora avaliar os conceitos contemporâneos de direitos fundamentais, e então identificar os aspectos constitucionais envolvidos no presente estudo, para que se possa, finalmente, abordar a questão principal: É o desenvolvimento nacional sustentável um direito fundamental?

34. SARLET, Ingo Wolfgang. Op. cit., p. 71.

35. Sen, Amartya Kumar. Op. cit., p. 336.

36. Objeto de arbítrios e injustiças, o que pode ser comparado às privações de liberdade de Amartya Sen.

37. Sarlet, Ingo Wolfgang. Op. cit., p. 71. 


\section{CONSIDERAÇÕES SOBRE DIREITOS FUndAMENTAIS}

A noção de direitos fundamentais está atrelada a própria ideia de Estado de Direito e Constituição desde o século XVIII, com as revoluções burguesas e os novos paradigmas lançados por documentos como a histórica Declaração Francesa dos Direitos do Homem e do Cidadão de 26.08.1789, que em seu art. 16 previa que: "a sociedade em que não esteja assegurada a garantia dos direitos nem estabelecida a separação dos poderes não tem Constituição".

Klaus Stern se manifesta da seguinte forma sobre o tema: "As ideias de Constituição e direitos fundamentais são, no âmbito do pensamento da segunda metade do século XVIII, manifestações paralelas e unidirecionadas da mesma atmosfera espiritual. Ambas se compreendem como limites normativos ao poder estatal. Somente a síntese de ambas outorgou à Constituição a sua definitiva e autêntica dignidade fundamental". ${ }^{38}$

$\mathrm{Na}$ atualidade, esta correlação ainda é latente, tendo em vista a própria característica dos direitos fundamentais de indisponibilidade para o poder estabelecido, o que é tema tratado por Ingo Sarlet ${ }^{39}$ nos seguintes termos:

"A imbricação dos direitos fundamentais com a ideia específica de democracia é outro aspecto que impende seja ressaltado. Com efeito, verifica-se que os direitos fundamentais podem ser considerados simultaneamente pressuposto, garantia e instrumento do princípio democrático de autodeterminação do povo, por intermédio de cada indivíduo, mediante o reconhecimento do direito de igualdade (perante a lei e de oportunidades), de um espaço de liberdade real, bem como por meio da outorga do direito à participação (com liberdade e igualdade), na conformação da comunidade e do processo político, de tal sorte que a positivação e a garantia do efetivo exercício de direitos políticos podem ser considerados o fundamento funcional da democracia."

Evidente desde este momento que o reconhecimento de um direito fundamental significa dizer que este pertence ao alicerce do Estado em questão, determinando obrigações e reconhecendo direitos públicos subjetivos, posto que guia todas as relações entre o particular e o poder público, já que este segundo, embora legítimo e democrático, não tem disponibilidade sobre os direitos do primeiro. Há uma restrição óbvia na abrangência das decisões políticas.

38. Stern, Klaus. Das Staatsrecht der Bundesrepublik. Munchen: C.H. Beck, 1988. vol. III/1, p. 181.

39. SARLET, Ingo Wolfgang. A eficácia dos direitos fundamentais: uma teoria geral dos direitos fundamentais na perspectiva constitucional. 10. ed. 2. tir. Porto Alegre: Livraria do Advogado, 2010. p. 61. 
Esta matéria, no caso brasileiro, assumiu importância sem precedentes na Constituição Federal de 1988, visto que a mesma tem características históricas relevantes, como o fato de ter nascido em um período marcado pelo fim de longa restrição à participação popular nas decisões políticas da nação. A influência de Constituições formadas em momentos históricos semelhantes em outros Estados, também é importante, como, por exemplo, a Constituição Italiana de 1947 e a Lei Fundamental Alemã de 1949, ou ainda a Constituição da República Portuguesa de 1976 e a Constituição Espanhola de 1978.

Estas influências fizeram com que a Constituição Federal de 1988 trouxesse diversas inovações. Ingo Sarlet, sobre isso, diz que: "Dentre as inovações, assume destaque a situação topográfica dos direitos fundamentais, o que, além de traduzir maior rigor lógico, na medida em que os direitos fundamentais constituem parâmetro hermenêutico e valores superiores de toda a ordem constitucional e jurídica, também vai ao encontro da melhor tradição do constitucionalismo na esfera dos direitos fundamentais". ${ }^{40}$

Merece foco também nessa análise a inovação do disposto no art. $5 .^{\circ}, \S 1 .^{\circ}$, da CF/1988, que determina a aplicabilidade imediata dos direitos fundamentais, independente de norma infraconstitucional, afastando o que costumava ser chamado de aspecto programático. Resta aqui evidente a consolidação desta matéria como privilegiada e reforçada.

Não obstante, para este ensaio, a mais relevante das novidades está no parágrafo seguinte do mesmo artigo, visto que este abre o rol dos direitos fundamentais de forma sem paralelo, ao prever que "Os direitos e garantias expressos nesta Constituição não excluem outros decorrentes do regime e dos princípios por ela adotados, ou dos tratados internacionais em que a República Federativa do Brasil seja parte".

Para Ingo Sarlet, ${ }^{41}$ tendo em vista o previsto no art. $5 .^{\circ}, \S 2 .^{\circ}$, da CF/1988:

"Já podemos sustentar a existência de dois grandes grupos de direitos fundamentais, notadamente o direitos expressamente positivados (ou escritos), no sentido de expressamente positivados, e os direitos fundamentais não escritos, aqui genericamente considerados aqueles que não foram objeto de previsão expressa pelo direito positivo. (...) no que concerne ao segundo grupo, podemos distinguir também duas categorias. A primeira constitui-se dos direitos fundamentais implícitos, no sentido de posições fundamentais subentendidas nas normas definidoras de direitos e garantias fundamentais, ao passo que a

40. Idem, ibidem.

41. SARlet, Ingo Wolfgang. Dignidade da pessoa humana... cit., p. 87. 
segunda categoria corresponde aos direitos fundamentais que a própria norma contida no art. $5 .^{\circ}$, \& $2 .^{\circ}$, da $\mathrm{CF} / 1988$ denomina de direitos decorrentes do regime e dos princípios".

Levando estas novidades da Constituição Federal de 1988 em conta, bem como a natureza dos direitos fundamentais, Rober Alexy ${ }^{42}$ define os direitos fundamentais como: "aquelas posições que, do ponto de vista do direito constitucional, são tão relevantes, que seu reconhecimento ou não reconhecimento não pode ser deixado à livre disposição do legislador ordinário". Já se pode adotar um conceito de direitos fundamentais, apoiando-se mais uma vez em Ingo Sarlet ${ }^{43}$ sendo esta definição suficiente por hora:

"Direitos fundamentais são, portanto, todas aquelas posições jurídicas concernentes às pessoas, que, do ponto de visto do direito constitucional positivo, foram, por seu conteúdo e importância (fundamentalidade em sentido material), integradas ao texto da Constituição e, portanto, retiradas da esfera de disponibilidade dos poderes constituídos (fundamentalidade formal), bem como as que, por seu conteúdo e significado, possam lhes ser equiparados, agregando-se à Constituição material, tendo, ou não, assento na Constituição formal (aqui considerada a abertura material do catálogo).

Isto posto, passa-se a abordar tema fundamental para as pretensões deste ensaio, a necessária análise das características subjetivas e objetivas dos direitos fundamentais, com imediatos reflexos nas obrigações geradas para o Estado e, consequentemente, na exigibilidade dos direitos.

Quanto aos direitos subjetivos, classicamente nomeados direitos públicos subjetivos, a ideia é a de "proteção de uma determinada esfera de autorregulamentação ou de um espaço de decisão individual, tal como é associado a um certo poder de exigir ou pretender comportamentos ou de produzir autonomamente efeitos jurídicos", conceito trazido por Vieira de Andrade ${ }^{44}$ ao qual acrescenta-se a doutrina de Robert Alexy ${ }^{45}$ no que concerne o que se exige ou pretende, sendo os direitos de defesa ou de prestação, os direitos de liberdade,

42. Alexy, Robert. Theorie der Grundrechte. 2. ed. Frankfurt am Main: Suhrkamp, 1994. p. 407 ("Grundrechte des Grundgesetzes sind Positionen, die vom Standpunkt des Verfassungsrechts aus so wichtig sind, dass ihre Gewährung oder Nichtgewährung nicht de einfachen parlamentarischen Mehrheit überlasse warden kann").

43. Sarlet, Ingo Wolfgang. A eficácia dos direitos fundamentais... cit., p. 77.

44. Andrade, José Carlos Vieira de. Os direitos fundamentais na Constituição Portuguesa de 1976. Coimbra: Almedina, 1987. p. 163.

45. Alexy, Robert. Op. cit., p. 171. 
visto como os de negação de exigências e proibições e os direitos de poder, manifestando-se na forma de competências e autorizações. Destacando-se aqui a síntese de José Joaquim Gomes Canotilho sobre o tema: “(...) os direitos fundamentais são, em primeira linha, direitos individuais, do que resulta a constatação de que, em se encontrando constitucionalmente protegidos como direitos individuais, esta proteção dar-se-á sob a forma de direito subjetivo". ${ }^{46}$

Já a característica ou perspectiva objetiva dos direitos fundamentais determina que estes não se limitem a defesa de um indivíduo contra atos do Estado ou do Poder Público. Nas palavras de Pérez Luño ${ }^{47}$ "os direitos fundamentais passaram a apresentar-se no âmbito da ordem constitucional como um conjunto de valores objetivos básicos e fins diretivos da ação positiva dos Poderes Públicos, e não apenas garantias negativas dos interesses individuais (...)". Ingo Sarlet ${ }^{48}$ comenta sobre a lição do autor espanhol, destacando que "neste contexto, (o autor) aponta para a função legitimadora do Estado de Direito decorrente desta significação axiológica objetiva dos direitos fundamentais (...)".

No âmbito internacional esta visão de que os direitos fundamentais contem uma perspectiva objetiva não é nova, refletindo há anos nas decisões de importantes Cortes Constitucionais, como a Alemã (Bundesverfassungsgericht) com destaque para o caso "Lüth" (BVerfGE 7, 198 Lüth - Urteil) e a Espanhola, (Tribunal Constitucional) com destaque para a sentença proferida em recurso de inconstitucionalidade promovido pelo parlamento Basco (STC 25/1981, FJ 5. ${ }^{\circ}$ ).

Porém, o mais importante aqui é o desdobramento desta perspectiva objetiva dos direitos fundamentais no que concerne à Administração Pública, conforme explica Ingo Sarlet, ${ }^{49}$ um:

“(...) desdobramento estreitamente ligado à perspectiva objetivo-valorativa dos direitos fundamentais diz com o que se poderia denominar de eficácia dirigente que estes (inclusive os que precipuamente exercem a função de direitos subjetivos) desencadeiam em relação aos órgãos estatais. Neste contexto é que se afirma conterem os direitos fundamentais uma ordem dirigida ao Estado no sentido de que a este incumbe a obrigação permanente de concretização e realização dos direitos fundamentais."

46. Canotilho, José Joaquim Gomes. Direito constitucional. 5. ed. Coimbra: Almedina, 1992. p. 547.

47. Pérez Luño, Antonio-Enrique. Los derechos fundamentales. 6. ed. Madrid: Tecnos, 1995. p. 20.

48. Sarlet, Ingo Wolfgang. A eficácia dos direitos fundamentais... cit., p. 143.

49. Idem, p. 146. 
O alcance desta perspectiva objetiva dos direitos fundamentais é constante tema de acalorados debates, mas adotando-se as lições de Michael Sachs na Alemanha no que o autor chama de Ausstrahlungswirkung, ${ }^{50}$ ou ainda a semelhante lição de Vieira de Andrade em Portugal, aqui chamada de "Eficácia irradiante", ${ }^{11}$ estes direitos "forneceriam impulsos e diretrizes para a aplicação e interpretação do direito infraconstitucional, o que, além disso, apontaria para a necessidade de uma interpretação conforme os direitos fundamentais (...)" ${ }^{52}$

Esta construção possibilita imaginar que o direito fundamental ao desenvolvimento natural sustentável irá modificar os objetivos das contratações públicas, o que, em verdade já acontece no âmbito das licitações, com a alteração do art. 3. ${ }^{\circ}$ da Lei 8.666/1993 por meio da Lei 12.349/2010, que passou a vigorar da seguinte forma "A licitação destina-se a garantir a observância do princípio constitucional da isonomia, a seleção da proposta mais vantajosa para a administração e a promoção do desenvolvimento nacional sustentável (...)".

A quebra do binômio tradicional da licitação (isonomia + proposta mais vantajosa), por si só é tema para ensaios de grande fôlego, contudo, entende-se que a discussão aqui se trava em momento anterior, não cabendo exposições mais alongadas, mas valendo como exemplo dos reflexos da presente proposta.

Feitas as breves considerações sobre os conceitos de dignidade da pessoa humana, desenvolvimento sustentável e as correlações entre estes conceitos, ainda, considerações sobre o conceito de direitos fundamentais e as perspectivas subjetiva e objetiva que o compõem, cabe considerar finalizada a primeira parte deste ensaio.

Passemos agora à análise do desenvolvimento nacional sustentável e da dignidade da pessoa humana sob os parâmetros do conceito de direitos fundamentais, para que, então, possa-se cogitar conclusões sobre os efeitos desta proposta.

\section{DesenVOLVIMENTO NaCIONAL SUSTENTÁVEL E DIGNIDADE DA PESSOA HUMANA SOB A ÓTICA DOS PARÂMETROS DO CONCEITO ADOTADO DE DIREITOS FUNDAMENTAIS}

Esta análise acontecerá da seguinte forma: inicialmente serão feitas considerações sobre a dignidade da pessoa humana em relação aos direitos funda-

50. SACHS, Michael (org.). Grundgesetz-Kommentar. Munchen: C.H. Beck, 1996. p. 79.

51. Andrade, José Carlos Vieira de. Op. cit., p. 168.

52. SARLET, Ingo Wolfgang. A eficácia dos direitos fundamentais... cit., p. 147. 
mentais. Em seguida, explorar-se-á a relação entre os direitos fundamentais e o desenvolvimento sustentável tripartido em desenvolvimento econômico, social e ambiental, todos aspectos previamente identificados, demonstrando-se a existência destes aspectos de forma já positivada e reconhecida como parte do corpo dos direitos fundamentais da Constituição Federal de 1988.

De modo análogo à Lei Fundamental Alemã e a Constituição Italiana, a Constituição Federal de 1988 reconhece a dignidade da pessoa humana como fundamento do Estado Democrático Brasileiro, sendo, portanto, possível estender a ideia de Franco Bartolomeni, ${ }^{53}$ de que estas são Constituições humanas por excelência. O que significa dizer, nas palavras de Jorge Miranda, ${ }^{54}$ que:

"A Constituição (...) confere uma unidade de sentido, de valor e de concordância prática ao sistema de direitos fundamentais, que, por sua vez, repousa na dignidade da pessoa humana, isto é, na concepção que faz da pessoa fundamento e fim da sociedade e do Estado, razão pela qual se chegou a afirmar que o princípio da dignidade da pessoa humana atua como 'alfa e ômega' do sistema das liberdades constitucionais e, portanto, dos direitos fundamentais."

Na visão de Winfried Brugger, “(...) a dignidade da pessoa humana é critério aferidor da legitimidade substancial de uma determinada ordem jurídico-constitucional, já que condiz com os fundamentos e objetivos, em suma, com a razão de ser do próprio poder estatal". ${ }^{55}$ Esta perspectiva demonstra claramente a importante influência que este fundamento, eleito constitucionalmente como tal no Brasil, deve ter na tomada das decisões políticas e jurídicas, atuando como guia.

Neste diapasão, é importante aqui saber que há uma vinculação especial entre os direitos fundamentais reconhecidos na Constituição Federal de 1988 e o princípio da dignidade da pessoa humana, sendo possível reconhecer direitos que são explicitações em primeiro grau da dignidade e outros que destes são decorrentes. ${ }^{56}$

A importância fundamental desta ligação entre direitos fundamentais e o princípio da dignidade da pessoa humana, para fins de reconhecimento do

53. Bartolomeni, Franco. La dignitá umana come concetto e valore constituzionale. Torino: G. Giappichelli, 1987. p. 11.

54. Miranda, Jorge. Manual de direito constitucional. 3. ed. Coimbra: Coimbra Ed., 2000. vol. IV. p. 180.

55. Brugger, Winfried. Menschenwürde, Menschenrechte, Grundrechte. Baden-Baden: Nomos, 1996. p. 5.

56. Sarlet. A eficácia dos direitos fundamentais... cit., p. 101. 
direito ao desenvolvimento nacional sustentável, é o reflexo do princípio (e sua carga normogenética, conforme já explorado) no catálogo aberto pelo art. $5 .^{\circ}, \S 2 .^{\circ}$, (também já abordado), nos termos de Ingo Sarlet "(...) importa que se deixe consignado como o princípio da dignidade da pessoa humana alcança operatividade neste contexto". ${ }^{57}$

Afora a utilização de um princípio como veículo para adentrar o desejado rol por meio da abertura de catálogo promovida pelo citado art. $5 .^{\circ}, \S 2 .^{\circ}$, da $\mathrm{CF} / 1988$, pode haver outro caminho para o desenvolvimento nacional sustentável, em verdade, o conceito adotado permite encontrar diversos aspectos já reconhecidos como direitos fundamentais, uma vez que se realiza a tripartição deste e analisa-se cada uma das partes individualmente.

Antes, deve-se ressaltar que o desenvolvimento nacional sustentável está presente também no preâmbulo da Constituição Federal de 1988, que, apesar de não ter natureza jurídica e sim política, norteia a interpretação constitucional, conforme já se manifestou o STF na ADIn 2.649, voto da rel. Min. Cármen Lúcia, julgamento em 08.05.2008, Plenário, DJ 17.10.2008.

Traçada a linha objetiva, o primeiro aspecto a ser explorado será o social. Segundo Rodrigo Machado Vilani, ${ }^{58}$ este primeiro aspecto tem como um dos principais componentes a criação de novos postos de trabalho visando a obtenção de renda individual adequada, semelhante à noção de facilidades econômicas como liberdade de Amartya Sen ${ }^{59}$ já tratada anteriormente, encontrando respaldo no art. $1 .^{\circ}$, III e IV, art. $3 .^{\circ}$, III, $7 .^{\circ}$ e 170 , VII, destacando-se que o art. 7. ${ }^{\circ}$ pertence topograficamente ao rol dos direitos fundamentais, visto que pertence ao Capítulo II do Título II da Constituição Federal de 1988.

Acrescente-se aqui o art. $6^{\circ}{ }^{\circ}$ também localizado topograficamente no rol dos direitos fundamentais, e que traz diversos direitos que estão compreendidos no conceito de oportunidades sociais de Amartya Sen ${ }^{60}$ com especial destaque para o direito a saúde, educação e alimentação, reforçadas todas as considerações sobre estes direitos citados como meio para o fim dignidade da pessoa humana.

57. Idem, p. 119.

58. VILANI, Rodrigo Machado. A aplicação do conceito constitucional de desenvolvimento sustentável sob a perspectiva do STJ e do STF. Revista Brasileira de Direito Constitucional 13/63.

59. Sen, Amartya Kumar. Op. cit., p. 55.

60. Idem, p. 56. 
O aspecto seguinte é o econômico, que, segundo Rodrigo Machado Vilani, ${ }^{61}$ compõe-se de um fluxo permanente de investimentos públicos e privados, manejo eficiente de recursos, absorção pela empresa de custos ambientais, endonegeização (contar com suas próprias forças), visando aumento da produção e da riqueza social sem dependência externa. O artigo que o autor identifica aqui é o 170 . Interessante adicionar a este o art. $5^{\circ}$, XIII, visto que se aborda aqui o desenvolvimento voltado para a pessoa humana, logo a liberdade de exercício profissional é fundamental para a participação econômica. A importância do art. 5. ${ }^{\circ}$ está também na posição topográfica, mais uma vez incluída no rol de direitos fundamentais.

Mantendo-se na esfera do aspecto econômico, pode-se acrescentar a este embasamento constitucional, com base na lição de Afonso Heck, ${ }^{62}$ o art. 174 da CF/1988, posto que este "caracteriza a passagem da concepção de um Estado ausente para um Estado presente no setor econômico".

Finalmente, o último dos três aspectos é o ambiental, abrangendo mais uma vez, segundo Rodrigo Machado Vilani, ${ }^{63}$ uma produção que respeita os ciclos ecológicos dos ecossistemas, a prudência na utilização dos recursos naturais não renováveis, de prioridade à produção de biomassa e à industrialização de insumos naturais renováveis, objetive a redução da intensidade energética e aumento da conservação de energia e utilize de tecnologias e processos produtivos de baixo índice de resíduos, tudo isso pautado por uma noção geral de cuidados ambientais.

Aqui, o objetivo maior é, ainda segundo o autor, "a melhoria da qualidade do meio ambiente e preservação das fontes de recursos energéticos e naturais para as próximas gerações", ${ }^{64}$ o que é marca característica dos direitos fundamentais de $3 .^{a}$ dimensão, sobre estes, vale lembrar a lição de Jairo Schäfer: ${ }^{65}$

"Com a evolução da sociedade, a crescente complexidade das relações intersubjetivas, decorrente do pluralismo e das contradições da sociedade contemporânea, revelou a inadequação de uma teoria tradicional dos direitos fundamentais que tem por paradigma exclusivo a ética individualista, o qual está

61. Vilani. Op. cit., p. 7.

62. Heck, Luis Afonso. Prefácio. In: Rocha Scott, Paulo Henrique. Direito constitucional econômico: Estado e normalização da economia. Porto Alegre: Safe, 2000. p. 3.

63. Vilani. Op. cit., p. 7.

64. Idem, ibidem.

65. SCHäFER, Jairo. Classificação dos direitos fundamentais: do sistema geracional ao sistema unitário - uma proposta de compreensão. Porto Alegre: Livraria do Advogado, 2005. p. 31. 
em colisão com uma sociedade que exige uma macroética na qual as responsabilidades e as relações mostram essencialmente coletivas."

O respaldo legal deste aspecto é o art. 170, VI e o art. 225 da CF/1988. Este último apresenta uma particularidade, já foi reconhecido como direito fundamental em repetidas decisões do STF, como por exemplo: ADPF 101, Plenário, j. 25.06.2008, rel. Min. Cármen Lúcia. MS 22.164, Pleno, j. 30.10.1995, rel. Min. Celso de Mello; RE 134.297, j. 13.06.1995, rel. Min. Celso de Mello.

Não obstante esteja finalizada a análise dos três principais aspectos do conceito de desenvolvimento sustentável frente à Constituição Federal 1988, há ainda uma última consideração a ser feita, o reconhecimento do direito ao desenvolvimento, como direito humano, em tratados internacionais dos quais o Brasil é signatário, hipótese também do art. 5. $^{\circ}$, § 2. ${ }^{\circ}$, da CF/1988 para entrada no rol dos direitos fundamentais.

Neste sentido, ensina Carlos García Bauer ${ }^{66}$ que: "do grupo dos quatro direitos denominados da 'terceira geração' dos direitos humanos ou direitos de solidariedade, foi o direito ao desenvolvimento o primeiro a ser reconhecido como direito humano. De fato, em 1977, a Comissão de Direitos Humanos das Nações Unidas o reconheceu como tal e quatro anos depois, em 14.12.1981, por 135 votos contra 1 e 13 abstenções, a Assembleia Geral da Organização Mundial, em sua Res. 36/133, aprovou que o direito ao desenvolvimento é um direito humano inalienável, declaração reiterada enfaticamente em 16.12.1983, em sua Res. 38/124, pedindo, desta feita, à referida Comissão de Direito Humanos adotar as medidas necessárias para promovê-lo. O status jurídico do direito ao desenvolvimento como direito humano inalienável já foi aceito, pois, universalmente".

A Res. ONU 41/128 é ainda mais enfática sobre o assunto, quando em seu art. 1..$^{\circ}$ prevê que o direito ao desenvolvimento é "um direito humano inalienável, em virtude do qual toda pessoa e todos os povos estão habilitados a participar do desenvolvimento econômico, social, cultural e político, a ele contribuir e dele desfrutar, no qual todos os direitos humanos e liberdades fundamentais possam ser plenamente realizados".

Há diversos outros exemplos de tratados internacionais que abordam o tema, vários dos quais o Brasil é signatário, assim como o é dos citados aqui. Estes tratados refletem uma ideia magistralmente sintetizada por Guilherme Amorim Campos da Silva ${ }^{67}$ quando diz que "O direito ao desenvolvimento

66. Bauer, Carlos García. Los derechos humanos em América. Guatemala: C.A., 1987. p. 78.

67. Silva, Guilherme Amorim Campos da. Direito ao desenvolvimento. São Paulo: Método, 2004. p. 73. 
é uma síntese dos direitos fundamentais, na exata medida em que aglutina a possibilidade do ser humano realizar integralmente as suas potencialidades e em todas as áreas do conhecimento".

Aqui é necessário ressalvar o disposto no art. 5. ${ }^{\circ}, \S 3 .^{\circ}$, da CF/1988 quanto à entrada dos tratados internacionais no ordenamento jurídico pátrio, porém, não sendo este o objetivo primordial do presente ensaio, a lição de Celso Lafer ${ }^{68}$ sobre o assunto encerrará este comentário:

"O \& 2. ${ }^{\circ}$ do art. $5 .^{\circ}$ suscitou controvérsias, pois arguiu-se que, a ser aplicado literalmente, ensejaria mudança constitucional por maioria simples, que é a maioria requerida para a aprovação de decreto legislativo que recepciona um tratado na ordem jurídica interna (...) foi por conta desta controvérsia que a EC 45/2004, também adicionou ao art. $5 .^{\circ}$, em consonância com o art. 60 , § $2 .^{\circ}$, da CF/1988, o novo \& 3. ${ }^{\circ}\left(\right.$... ). O novo $\& 3 .^{\circ}$ do art. $5 .^{\circ}$ pode ser considerado como uma lei interpretativa destinada a encerrar as controvérsias jurisprudenciais e doutrinarias suscitadas pelo $\S 2 .^{\circ}$ do art. 5. . ."

Isto posto, resta realizada a proposta inicial de análise e intercambiamento de conceitos, o que permite a apresentação das conclusões, acompanhadas das possíveis consequências do reconhecimento do direito ao desenvolvimento como direito fundamental. É cristalino que as consequências aqui são hipóteses trabalhadas em situações que guardam semelhança com o direito ao desenvolvimento, como, por exemplo, a efetivação de direitos sociais.

\section{Conclusões}

Durante a exploração dos vários conceitos necessários para este ensaio, restou claro que há uma permeabilidade entre a dignidade da pessoa humana, o desenvolvimento nacional sustentável e os direitos fundamentais, sendo inegável que existe um reconhecimento ao desenvolvimento em suas três facetas, quais sejam ambiental, social e econômico na Constituição Federal de 1988, o que possibilita incipientes conclusões.

Inicialmente, não há nada que obste o reconhecimento do desenvolvimento nacional sustentável como direito fundamental, fazendo-se isto por meio do princípio da dignidade da pessoa humana, o qual atua como balizador do regime de princípios constantes da Constituição Federal de 1988 (hipótese do art. 5. $\left.{ }^{\circ}, \S 2 .^{\circ}\right)$.

68. LAFEr, Celso. A internacionalização dos direitos humanos: Constituição, racismo e relações internacionais. São Paulo: Manole, 2005. p. 15. 
Em segundo lugar, o reconhecimento do art. $3 .^{\circ}$, II, como direito fundamental, mesmo que fora do rol do Título II da Constituição Federal de 1988 é plenamente possível ainda que este já seja um objetivo fundamental, pois sua característica reforça esta possibilidade já que "o desenvolvimento não é uma finalidade a se alcançar, mas um processo contínuo da melhoria das condições de vida". ${ }^{69}$

Seguindo esta linha de raciocínio, Ingo Sarlet ${ }^{70}$ já se manifestou sobre a dignidade da pessoa humana (fundamento da República Federativa do Brasil), lição plenamente intercambiável para este caso:

"(...) a discussão em torno da qualificação da dignidade da pessoa humana como princípio ou direito fundamental não deve ser hipostasiada, já que não se trata de conceitos antitéticos e reciprocamente excludentes (notadamente pelo fato de as próprias normas de direitos fundamentais terem cunho eminentemente - embora não exclusivamente - principiológico) (...) do próprio princípio da dignidade da pessoa (isoladamente considerado) podem e até mesmo devem ser deduzidos direitos fundamentais autônomos, não especificados (e, portanto, também se poderá admitir que - neste sentido - se trata de uma norma de direito fundamental).

Ademais, os vários aspectos deste conceito já estão, conforme demonstrado, permeando todo o ordenamento constitucional pátrio.

Que não se deixe de lado a questão dos tratados internacionais, dos quais o Brasil é signatário, que já reconheceram o direito ao desenvolvimento como direito humano, gerando a possibilidade de adoção deste conceito como direito fundamental por meio das regras de recepção destes tratados, já debatidas anteriormente.

Em síntese, não há razão que exclua a possibilidade de um novo direito fundamental, qual seja o direito ao desenvolvimento. Em verdade, este reconhecimento é, de certa forma, lógico, tendo em vista a própria natureza do Estado Social e os objetivos que este visa alcançar. Uma resistência aqui, provavelmente partiria de uma concepção liberal mais pura de Estado, entretanto, seria necessário questionar a compatibilidade desta com a Constituição Federal de 1988.

69. Rattner, H. Desenvolvimento sustentável: tendências e perspectivas. In: MagalHÃEs, L. E. (org.). A questão ambiental. São Paulo: Terragraph, 1994. p. 4.

70. SARlet, Ingo Wolfgang. Dignidade da pessoa humana... cit., p. 83-84. 
O que é mais interessante, em verdade, são as consequências da realização desta possibilidade, e não a realização propriamente dita. Visto que, conforme ensina Arjun Sengupta: ${ }^{11}$

"O direito ao desenvolvimento, quando aceito como um direito humano através de um processo legítimo de consenso, portanto, torna-se um clamor primário sobre os recursos de um país - quando os recursos são tomados em seu sentido mais amplo, como sendo qualquer instrumento necessário para alcancar certos objetivos - físicos, financeiros ou institucionais."

E é aqui que as questões sobre perspectivas objetivas e subjetivas dos direitos fundamentais ganham em importância. Uma vez reconhecido o direito fundamental ao desenvolvimento nacional sustentável, uma contratação pública feita sem o devido cuidado de promover este direito, pode gerar a responsabilização do agente estatal responsável (caráter objetivo), bem como a possibilidade de uma responsabilização do Estado por agressão à esfera de direitos individuais (caráter subjetivo).

A responsabilidade por definir o verdadeiro alcance jurídico deste direito, evitando o risco de um genérico "direito fundamental a dignidade", recairá sem dúvida ao Judiciário. Hoje resta impositiva a necessidade de repensar a posição deste com relação à realização dos direitos fundamentais e é urgente a concepção do juiz como realizador dos fins sociais da lei. ${ }^{72}$ É isto que Andreas $\mathrm{Krell}^{73}$ ensina:

"Apesar do fato de a doutrina constitucional moderna no Brasil enfatizar que o Estado Social preconizado pela Carta de 1988 exige um novo entendimento das suas normas jurídicas, orientado por valores, a maioria dos operadores (juízes, promotores, procuradores, administradores, advogados) ainda não passou a interpretar as normas constitucionais e ordinárias (civis, administrativas) 'no espírito' dos direitos fundamentais e seus valores subjacentes".

Aqui vale a lembrança da lição de Ronald Dworkin ${ }^{74}$ ao afirmar que: "O objetivo da decisão judicial constitucional não é meramente nomear direitos,

71. Sengupta, Arjun. O direito ao desenvolvimento como um direito humano. A verdadeira liberdade individual não pode existir sem segurança econômica e independência. Revista da Social Democracia Brasileira 68/74.

72. Bittencourt, Marcus Vinicius Corrêa. Estudos de direito público. Belo Horizonte: Fórum, 2008. p. 97.

73. Krell, Andreas J. Direitos sociais e controle judicial no Brasil e na Alemanha: os (des) caminhos de um direito constitucional comparado. Porto Alegre: Fabris, 2002. p. 53.

74. Dworkin, Ronald. O império do direito. São Paulo: Martins Fontes, 1999. p. 37. 
mas assegurá-los, e fazer isso no interesse daqueles que têm tais direitos". Não poderia ser diferente o entendimento da necessidade de um Judiciário atuando nestes moldes, visto que se este não assegura os direitos na omissão do Estado, esvazia ações como o mandado de injunção ou mesmo a ação direta de inconstitucionalidade por omissão.

Em resumo, o Estado Social, reconhecido na Constituição Federal de 1988, tem um fim. Este fim é o bem-estar e as liberdades do ser humano. O desenvolvimento nacional sustentável é o direito fundamental que irá garantir que as ações deste Estado estejam corretamente balizadas para atingir este fim.

\section{REFERÊNCIAS BIBLIOGRÁFICAS}

Alexandrino, José de Melo. Perfil constitucional da dignidade da pessoa humana: um esboço traçado a partir da variedade de concepções. Estudos em honra ao Professor Jose Ascensão. Coimbra: Almeida, 2008. vol. I.

Alexy, Robert. Theorie der Grundrechte. 2. ed. Frankfurt am Main: Suhrkamp, 1994.

Andrade, José Carlos Vieira de. Os direitos fundamentais na Constituição Portuguesa de 1976. Coimbra: Almedina, 1987.

Bartolomeni, Franco. La dignitá umana come concetto e valore constituzionale. Torino: G. Giappichelli, 1987.

Bauer, Carlos García. Los derechos humanos em América. Guatemala: C.A., 1987.

Bittencourt, Marcus Vinicius Corrêa. Estudos de direito público. Belo Horizonte: Fórum, 2008.

BRugGer, Winfried. Menschenwürde, Menschenrechte, Grundrechte. Baden-Baden: Nomos, 1996.

Canotilho, José Joaquim Gomes. Direito constitucional. 5. ed. Coimbra: Almedina, 1992.

Comissão Mundial sobre o Meio Ambiente e Desenvolvimento (WCED). Our common future. Oxford: Oxford University Press, 1987.

Dworkin, Ronald. O império do direito. São Paulo: Martins Fontes, 1999.

Heck, Luis Afonso. Prefácio. In: Rocha Scott, Paulo Henrique. Direito constitucional economico: Estado e normalização da economia. Porto Alegre: Safe, 2000.

Krell, Andreas J. Direitos sociais e controle judicial no Brasil e na Alemanha: os (des) caminhos de um direito constitucional comparado. Porto Alegre: Fabris, 2002.

Lafer, Celso. A internacionalização dos direitos humanos: Constituição, racismo e relações internacionais. São Paulo: Manole, 2005.

Maunz, Theodor; Zippelius, Reinhold. Deutsches Staatsrecht. 29. ed. Munchen: C.H. Beck, 1994. 
Meadows, Donella H.; Meadows, Dennis L.; Randers, Jorgen; Behrens, William W. Limites do crescimento: um relatório para o projeto do clube de Roma sobre o dilema da humanidade. 2. ed. São Paulo: Perspectiva, 1978.

Miranda, Jorge. Manual de direito constitucional. 3. ed. Coimbra: Coimbra Ed., 2000. vol. IV.

Pérez Luño, Antonio-Enrique. Los derechos fundamentales. 6. ed. Madrid: Tecnos, 1995.

Rattner, H. Desenvolvimento sustentável: tendências e perspectivas. In: MagaLHÃES, L. E. (org.). A questão ambiental. São Paulo: Terragraph, 1994.

SACHS, Ignacy. A terceira margem: em busca do ecodesenvolvimento. São Paulo: Cia. das Letras, 2009.

Rumo à ecossocioeconomia: teoria e prática do desenvolvimento. São Paulo: Cortez, 2007.

SACHS, Michael (org.). Grundgesetz-Kommentar. Munchen: C.H. Beck, 1996.

SARLET, Ingo Wolfgang. Dignidade da pessoa humana e direitos fundamentais na Constituição Federal de 1988. 9. ed. Porto Alegre: Livraria do Advogado, 2011.

A eficácia dos direitos fundamentais: uma teoria geral dos direitos fundamentais na perspectiva constitucional. 10. ed. 2. tir. Porto Alegre: Livraria do Advogado, 2010.

SCHÄFER, Jairo. Classificação dos direitos fundamentais: do sistema geracional ao sistema unitário - Uma proposta de compreensão. Porto Alegre: Livraria do Advogado, 2005.

Sen, Amartya Kumar. Desenvolvimento como liberdade. São Paulo: Cia. das Letras, 2000.

Sengupta, Arjun. O direito ao desenvolvimento como um direito humano. A verdadeira liberdade individual não pode existir sem segurança econômica e independência. Revista da Social Democracia Brasileira. n. 68. p. 74. Disponível em: [http://wwl.psdb.org.br/psdb_antigo/Partido/itv/revista/revista_02/p7292_o_direito.pdf]. Acesso em: 17.10.2011.

SiLva, Geraldo Eulálio do Nascimento. Direito ambiental internacional. 2. ed. Rio de Janeiro: Thex, 2002.

SiLva, Guilherme Amorim Campos da. Direito ao desenvolvimento. São Paulo: Método, 2004.

Stern, Klaus. Das Staatsrecht der Bundesrepublik. Munchen: C.H. Beck, 1988. vol. III/1.

VILANI, Rodrigo Machado. A aplicação do conceito constitucional de desenvolvimento sustentável sob a perspectiva do STJ e do STF. Revista Brasileira de Direito Constitucional. n. 13. p. 63. São Paulo: Escola Superior de Direito Constitucional, jan.-jun. 2009. 


\section{Pesouisas do Editorial}

\section{Veja também Doutrina}

- Análise do desenvolvimento sob a perspectiva da Constituição brasileira, de Rogério Emilio de Andrade - $R D C / 23 / 262$;

- Considerações a respeito da Lei 12.349, de 15.12.2010, de Lair da Silva Loureiro Filho RT 911/21;

- Direitos humanos, o princípio da dignidade humana e a Constituição brasileira de 1988, de Flávia Piovesan - RT833/41; e

- Transformação da economia direcionada ao crescimento e ao alcance do progresso social, sob a égide da Constituição Federal de 1988, de Dinaura Godinho Pimentel Gomes - $R D C l 66 / 170$. 